\title{
ABORDAGEM HÍBRIDA NO ENSINO SUPERIOR: REFLEXÕES TEÓRICO-METODOLÓGICAS
}

\author{
ENFOQUE HÍBRIDO EN LA ENSEÑANZA SUPERIOR: \\ REFLEXIONES TEÓRICO-METODOLÓGICAS
}

HYBRID APPROACH IN HIGHER EDUCATION:
THEORETICAL-METHODOLOGICAL REFLECTIONS

\author{
Elisabete CERUTTI ${ }^{1}$ \\ Lucimauro Fernandes de MELO ${ }^{2}$
}

RESUMO: O estudo em questão versa acerca de conceitos teórico-metodológicos construídos no Grupo de Pesquisa em Educação e Tecnologias - GPET, na Universidade Regional Integrada do Alto Uruguai e das Missões - URI Campus de Frederico Westphalen - RS. Objetiva abordar o Ensino Híbrido como fonte de práticas interativas no Ensino Superior. Tem como metodologia o estudo qualitativo, através da pesquisa teórica, e traz em seu referencial os principais expoentes: Prensky (2010), Christensen (2015), Bacich (2015). As instituições vêm recebendo uma geração nativa digital que expressa seus saberes e desejos de aprender, tendo a tecnologia como uma forte aliada. Urge preparar o professor para uma prática reflexiva, à inovação e à interação. Como conclusão, os pressupostos do Ensino Híbrido aliam a interatividade e o conhecimento, tão necessários a esta geração que chegou à universidade, e que possibilitam ao professor instituir uma metodologia que proponha a ampla troca de ideias e a capacidade de dialogar sobre conteúdos de maneira interativa e diferenciada.

Palavras-chave: Ensino híbrido. Professor. Ensino superior.

RESUMEN: El estudio en cuestión versa conceptos teórico-metodológicos construidos en el Grupo de Investigación en Educación y Tecnologías - GPET, en la Universidad Regional Integrada del Alto Uruguay y de las Misiones - URI Câmpus de Frederico Westphalen - RS. Objetivo abordar la Enseñanza Híbrida como fuente de prácticas interactivas en la Enseñanza Superior. La metodología es el estudio cualitativo, a través de la investigación teórica y trae en su referencial a los principales exponentes: Prensky (2010), Christensen (2015), Bacich (2015). Las instituciones vienen recibiendo una generación nativa digital que expresa sus saberes y deseos de aprender, teniendo la tecnología como una fuerte aliada. Es urgente preparar al profesor para una práctica reflexiva, a la innovación ya la interacción. Como conclusión, los

\footnotetext{
${ }^{1}$ Universidade Regional Integrada do Alto Uruguai e das Missões (URI) - Frederico Westphalen - RS Brasil. Docente do Departamento de Ciências Humanas. Doutora em Educação. Líder do Grupo de Pesquisa em Educação e Tecnologias GPET e membro do Grupo de Pesquisa em Educação. beticerutti@uri.edu.br

${ }^{2}$ Universidade Regional Integrada do Alto Uruguai e das Missões (URI) - Frederico Westphalen - RS Brasil. Docente do Departamento de Ciências Humanas. Mestre em Educação e Doutoranda em Geriatria e Gerontologia PUC RS. lucimauro@uri.edu.br
} 
presupuestos de la Enseñanza Híbrida alian la interactividad y el conocimiento, tan necesarios a esta generación que llegó a la universidad y posibilita al profesor instituir una metodología que proponga el amplio intercambio de ideas y la capacidad de dialogar sobre contenidos de manera interactiva y diferenciada.

PALABRAS-CLAVE: Enseñanza híbrida. Profesor. Enseñanza superior.

ABSTRACT: The study in question deals with theoretical and methodological concepts built in the Research Group on Education and Technologies - GPET, at the Integrated Regional University of Alto Uruguai and the Missions - URI Campus of Frederico Westphalen - RS. It aims to approach Hybrid Education as a source of interactive practices in Higher Education. Its methodology is the qualitative study, through the theoretical research and brings in its reference the main exponents: Prensky (2010), Christensen (2015), Bacich (2015). Institutions have been receiving a native digital generation that expresses their knowledge and desires to learn, with technology as a strong ally. It is urgent to prepare the teacher for reflexive practice, innovation and interaction. As a conclusion, the hypothesis of Hybrid Teaching combines the interactivity and knowledge so necessary to this generation that it arrived at the university and allows the teacher to institute a methodology that proposes the wide exchange of ideas and the ability to dialogue about contents in an interactive and differentiated way.

KEYWORDS: Hybrid teaching. Teacher. Higher education.

\section{Introdução}

Este estudo compartilha questões teórico-metodológicas objetivando abordar processos inovadores, que urgem ser incorporados aos aspectos didáticos no Ensino Superior. O mesmo é fruto dos estudos realizados pelo Grupo de Pesquisa em Educação e Tecnologias - GPET, na Universidade Regional Integrada do Alto Uruguai e das Missões - URI Campus de Frederico Westphalen - RS.

Os atuais avanços da Ciência e da Tecnologia têm provocado profundas transformações no comportamento social, nas formas de se comunicar, buscar e construir novos conhecimentos.

Nesse contexto, o espaço universitário, em especial no processo de aprendizagem, também sofre modificações, exigindo na formação de professores a inovação nos métodos pedagógicos. Conforme Lévy (1999), um novo tempo, um novo espaço e outras maneiras de pensar e fazer educação são exigidos na sociedade da informação. 
Para Valente (2014), as Tecnologias Digitais da Informação e da Comunicação TDICs nos possibilitam uma sala de aula que pode deixar de ser aquela onde os alunos se sentam em filas, voltados para o quadro. É imprescindível associar a cultura digital à formação do professor, uma vez que estamos considerando que a atuação profissional da educação está alicerçada no seu processo formativo, no qual se constrói a intencionalidade da profissão.

$\mathrm{O}$ acesso e o uso das TDICs no Ensino Híbrido acenam à necessidade de reorganização dos currículos, uma vez que em muitos deles não há a referência ao ensino não presencial e somente ao presencial. Assim, é importante potencializar as tecnologias como recursos pedagógicos, inovando as metodologias utilizadas na prática educacional. Nesse sentido, Kenski (2003) pondera que tais alterações resultam em mudanças sensíveis no contexto educacional, tornando-se necessário considerar que o acesso e a utilização das novas tecnologias condicionam o uso de metodologias emergentes, de práticas educativas inovadoras. Complementando a temática, Lévy (2004) vai além e profetiza que as estruturas centralizadas perderão seu sentido e darão lugar a atitudes mais abertas e colaborativas que, inevitavelmente, tornar-se-ão novas referências no campo educacional.

A intenção do trabalho colaborativo promove a integração das TDICs com os currículos, pois possibilita a aproximação da realidade escolar com o cotidiano do aluno imerso no mundo tecnológico. Também auxilia para um maior engajamento dos alunos no aprendizado, com ampliação do potencial e melhor aproveitamento do professor para intervenções efetivas. O resultado é um planejamento rico, individualizado e dinâmico.

Nesse sentido, emerge a abordagem híbrida, caracterizada segundo Christensen, Horn \& Staker (2013, p.7) como

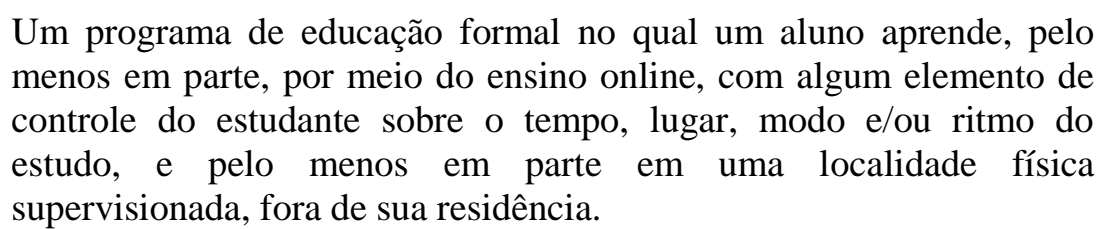

Imbuídos desse conceito, o ensino híbrido prevê a mediação do professor no processo de ensino-aprendizagem de forma dinâmica, reforçando a atitude investigativa do aluno, de forma que, de maneira conjunta, trabalhem em prol da construção do conhecimento. Esse diálogo entre professores e alunos se dá com a inserção das TDICs nas práticas docentes. 
É importante que os professores tenham clareza de que as TDICs caracterizamse como um conjunto de diferentes mídias, que envolvem as Tecnologias da Informação e Comunicação - TIC e as Tecnologias Digitais - TD, através da interação entre professor e aluno no ciberespaço. Considerando que o avanço tecnológico está em constante expansão, ele torna-se um espaço capaz de promover a aprendizagem. Almeida e Silva (2011, p.4) entendem que:

As TDICs na educação contribuem para a mudança das ráticas educativas com a criação de uma nova ambiência em sala de aula e na escola que repercute em todas as instâncias e relações envolvidas nesse processo. Dentre elas, as mudanças na gestão de tempos e espaços, nas relações entre ensino e aprendizagem, nos materiais de apoio pedagógico, na organização e representação das informações por meio de múltiplas linguagens.

Tendo em vista esses conceitos e reflexões, torna-se evidente que o Ensino Híbrido e os recursos das TDICs são possibilidades que, se bem exploradas como ferramenta educacional, promovem uma aprendizagem significativa e contextualizada. Segundo Moran (2007, p.2), "são pontes que abrem a sala de aula para o mundo".

Para o estudioso, os alunos têm acesso a uma grande variedade de informações de forma instantânea, contudo, para processá-las e interpretá-las é indispensável a mediação docente, no intuito de desenvolver nos alunos a capacidade de filtrar informações, a fim de transformá-las em conhecimento: papel único, exclusivo e insubstituível do professor. Dessa forma, Moran $(2007$, p. 2) sentencia que "o professor ajudará o aluno a questionar, a procurar novos ângulos, a relativizar dados, a filtrar conclusões".

Tal situação permite refletir sobre a revitalização das relações pedagógicas através do Ensino Híbrido entre professores e alunos para que, que forma efetiva, tornese qualitativa no ensino, com uma nova configuração da sociedade tecnológica.

A partir do olhar e da compreensão do outro, num trabalho interdisciplinar, muitos conceitos se relacionam e são aprendidos pelos múltiplos diálogos. Latour (2011) agrega-nos quando salienta que as descobertas da ciência podem ser consideradas por múltiplos profissionais. São esses atores, com uma diversidade de sujeitos envolvidos, que geram as concepções, produzindo discursos para ou sobre a ciência e a tecnologia, considerando-as como construções sociais. Há uma comunidade científica que se apoia na ciência, mas é preciso entender que há uma nova sociologia da ciência em que estão presentes diferentes atores para sua constituição. 
O avanço tecnológico tem afetado vários aspectos da vida, gerando novas ferramentas que aceleram a comunicação, transformam a produção, as relações dos homens entre si e suas atividades. Dessa forma, a própria organização da sociedade produz efeitos sociais que chamam a atenção das instituições de ensino e de seus profissionais.

O final do Século XX é evidenciado pelo processo de aceleração da globalização, no qual podemos perceber diferentes avanços que derrubaram fronteiras. Um exemplo disso é o avanço explosivo das tecnologias que permitiram a ampliação dos processos comunicativos, os quais se utilizam dos recursos tecnológicos como da mídia impressa, de linguagem radiofônica e, principalmente, do ambiente virtual que apresentou um visível crescimento em relação ao acesso e a navegação online, tornando a informação mais próxima dos sujeitos.

Em meio a essas novas manifestações, encontram-se as instituições educativas, como lugar em que o saber é matéria-prima. Todos os sujeitos educativos vêm sendo convidados a olhar para este contexto em que a aquisição rápida de informações pode gerar a assimilação de um novo conhecimento e refletir sobre estes processos de interação.

É neste contexto que urge preparar o educador para uma prática reflexiva, à inovação e à cooperação. Sendo o educador um profissional que está interligado à formação da consciência do ser humano, deve, indubitavelmente, ser uma pessoa de visão aberta, dinâmica e um profundo questionador do seu fazer e da realidade à sua volta, com competências e habilidades para dinamizar o processo de aprender e de ensinar, também, com o auxílio da tecnologia.

$\mathrm{Na}$ atualidade, muito se tem falado sobre "inovar no ensino", sobre tendências de metodologias ativas capazes de garantir maior aprendizagem e qualidade no ensino. Não se trata de mais um modismo na educação, mas de um olhar diante do que a oportuna relação educação e tecnologias pode oferecer aos educandos, educadores e instituições quando se reflete sobre as características de alunos que temos recebido hoje neste contexto cibercultural de que tratamos nesse ensaio.

Cerutti e Giraffa (2015) destacam que, com a tecnologia na sala de aula, o professor torna-se agente facilitador, auxiliando na aprendizagem de seus alunos e motivando-os para auxiliar em sua aula, como articuladores de novos espaços de aprendizagem. 
Ao abordar a prática educativa diante do perfil do professor e do aluno no contexto de cibercultura, expressamos o conceito de prática pedagógica, em que espaço se encontra e quais são os sujeitos inseridos.

\begin{abstract}
Na nova mídia digital, a comunicação, com efeito, é interativa em sentido simultaneamente específico e ampliado: ampliado, por um lado, porque permite a interação humana ativa e em mão dupla com os próprios meios e equipamento que a viabilizam; específico, de outro, porque essa circunstância permite ainda a interação social ativa e em mão dupla entre os seres humanos, ao ensejar o aparecimento de redes sociotécnicas participativas que transcendem a sua pura e simples interligação social, como ocorria na esfera da velha mídia. As redes sociais, portais e blogues, os videojogos, chats e sites de todo tipo, os sistemas de troca de mensagens e o comércio eletrônico, o cinema, rádio, música e televisão interativos via internet são, realmente, apenas algumas das expressões que surgem nesse âmbito e estão ajudando a estruturar praticamente a cibercultura. (RÜDIGER, 2011, p. 14).
\end{abstract}

Relacionado à educação, o processo interativo associa-se ao contato do aprendente com o objeto ou conteúdo a ser estudado. Neste momento, as ferramentas tecnológicas aparecem enquanto um objeto a ser manipulado para obter a essência de algo.

Quando se fala de aprendizagens interativas, podemos citar os jogos propriamente ditos, como riquíssimos em interação. Para isso, basta o professor atrelar o conteúdo estudado em sala de aula a um jogo disponível em rede que pode ser utilizado como revisão do que foi estudado até então, ou introdução de um saber.

\title{
Decifrando o ensino híbrido
}

Outro aspecto extremamente pertinente a ser considerado são os estudos sobre a personalização do ensino, propondo diferenciação na maneira de ensinar e de aprender, o que oferece ao sujeito um novo olhar diante de seu papel como aprendiz. Experiências que oportunizam aos alunos um histórico de participação em aulas, por vezes, com métodos que são focados no estilo palestra de ensinar, ao mesmo tempo em que temos alunos com características de aprendizagem que podem ser mais desafiados a aprender através de seu fazer, pensar e racionalizar.

Com a facilidade de acesso e de ambiência às tecnologias, estamos defendendo a ideia de que quando o aluno pode exercer sua autonomia, estamos oferecendo a ele a 
possibilidade de, através da tecnologia, aprender, ainda que nem sempre de maneira padronizada. Em suma, cada pessoa aprende melhor seguindo seu nível de proficiência em cada conteúdo. Em que sequência posso apresentar os conteúdos aos indivíduos, e com mais precisão atingir larga escala, foge do padrão de um conteúdo a ser apresentado de uma só maneira.

O Ensino Híbrido constitui-se em "uma tentativa de oferecer 'o melhor de dois mundos' - isto é, as vantagens da educação online combinadas com todos os benefícios da sala de aula tradicional." (CHRISTENSEN; HORN; STAKER, 2013, p. 3). O que conhecemos como "ensino tradicional" não é excluído das discussões acerca da formação. Também conhecido como blended learning:

É um programa de educação formal no qual um aluno aprende, pelo menos em parte, por meio do ensino online, com algum elemento de controle do estudante sobre o tempo, lugar, modo e/ou ritmo do estudo, e pelo menos em parte em uma localidade física supervisionada, fora de sua residência. (CHRISTENSEN; HORN; STAKER, 2013, p. 7)

Essa abordagem de ensino respeita o ritmo de aprendizagem de cada estudante e busca a personalização do ensino, visto que através dele é possível identificar o modo como cada sujeito aprende. Como as atividades didáticas não precisam ser iguais em todos os momentos, o professor consegue perceber quando os alunos estão ou não avançando em determinado conteúdo, tendo a liberdade de elaborar outra atividade em que esteja presente o aprendizado de cada aluno. Nesse sentido, é necessário criar:

Uma solução híbrida que dê aos educadores o melhor dos dois mundos - isto é, as vantagens do ensino on-line combinados com todos os benefícios da sala de aula tradicional. A opção disruptiva é empregar o ensino on-line em novos modelos que se afastem da sala de aula tradicional e foquem inicialmente nos não consumidores que valorizam a tecnologia pelo que ela é - mais adaptável, acessível e conveniente. (CHRISTENSEN, HORN; STAKER, 2013, p. 15)

Neste propósito, estamos trabalhando com tecnologias que estejam a serviço da aprendizagem, exploradas a ponto de maximizar os conhecimentos e desenvolver habilidades nos estudantes, fazendo sentido o uso da tecnologia para ler, escrever, aprender, superando a visão de usar a tecnologia somente para uma ambiência social. É neste contexto de segurança da intencionalidade pedagógica do recurso para a sala de aula, no despertar de sua criatividade, que o professor, também, vai se desafiando, conforme ressaltam Bacich, Neto e Trevisani. 


\begin{abstract}
A integração das tecnologias digitais na educação precisa ser feita de modo criativo e crítico, buscando desenvolver a autonomia e a reflexão dos seus envolvidos, para que eles não sejam apenas receptores de informações. O projeto político-pedagógico da escola que queira abarcar essas questões precisa ponderar como fazer essa integração das tecnologias digitais para que os alunos possam aprender significativamente em um novo ambiente, que agora contempla o presencial e o digital. $(2015$, p. 47)
\end{abstract}

Cabe à formação docente e aos espaços formativos dentro das Instituições de Ensino Superior, a possibilidade de criação de políticas de gestão que ofereçam ao professor o espaço para inovar. Ao conhecer e interagir com as tecnologias digitais, ele mesmo vai se empoderando de buscar cursos de formação que o prepare para utilizar das tecnologias com segurança.

Quando pautamos o Ensino Superior, é porque temos o exercício da aprendizagem profissional que necessita estar presente e com efetivo saber. $\mathrm{O}$ ensino híbrido é capaz de oferecer a meta-aprendizagem, porque dispõe ao aluno essa corresponsabilidade ao oferecer novas condições de aprender, porque ele é sujeito do processo, e através de ferramentas tecnológicas, o acesso ao conteúdo da aula torna-se cada vez mais ágil e possível. É por isso que "a sala de aula" como um espaço diferenciado de aprendizagem muda, também, sua concepção. A sala de aula tradicional, com carteiras alinhadas, dá espaço para uma sala de aula que inicia o conteúdo em qualquer outro ambiente, e que ao chegar ao espaço "sala", o mais importante é o movimento do mobiliário que traz novos sentidos à aula, com a visibilidade que o ensino e a aprendizagem ganhem mais vida e significado.

Com professores comprometidos e dispostos a inovar, alunos com sede de aprender de maneiras diferentes, pais incentivadores e uma gestão que prime por um ensino de qualidade, o Ensino Híbrido tende a se concretizar em uma excelente alternativa de tornar a escola um espaço mais amplo e atual de aprendizagem. Assim,

O ensino híbrido vem ao encontro das necessidades recentes de descobrir a melhor prática educativa para professores e escolas. Trata-se de um modelo de ensino que pressupõe o uso da tecnologia para o desenvolvimento das atividades dentro e fora da classe, em que o aluno é estimulado a buscar o conhecimento com a mediação do professor e da escola. (SILVA; CAMARGO, 2015. p. 181)

O Ensino Híbrido possibilita uma flexibilidade no planejamento, tirando o foco do ensino somente em sala de aula, pois o conhecimento é compartilhado através de vários meios e assimilado em diferentes ambientes. $\mathrm{O}$ aluno é motivado a participar 
mais ativamente das aulas, interagindo e fazendo associações com as suas vivências. $\mathrm{O}$ desafio da escola é grande e a equipe de professores precisa estar empenhada em auxiliar os estudantes para que tenham um futuro próspero e estejam preparados para enfrentar a vida em todos os seus sentidos. Para isso:

As metodologias precisam acompanhar os objetivos pretendidos. Se queremos que os alunos sejam proativos, precisamos adotar metodologias nas quais eles se envolvam em atividades cada vez mais complexas, em que tenham de tomar decisões e avaliar os resultados, com apoio de materiais relevantes. Se queremos que sejam criativos, eles precisam experimentar inúmeras novas possibilidades de mostrar sua iniciativa. (MORAN, 2007, p. 34)

Dessa forma, o professor deve propor atividades desafiadoras aos estudantes para que os mesmos exercitem sua criatividade e desenvolvam diferentes habilidades e competências. O trabalho com tecnologias vem de encontro a isso e mune o professor com diferentes alternativas para dar mais dinamicidade às suas aulas. Vivemos em uma era de mudanças, onde inovações surgem todos os dias e os alunos devem ser formados de acordo com a realidade social em que estão inseridos.

Nesse aspecto, o ganho maior é do aluno que interage e faz, o que repercute com a aprendizagem. $\mathrm{O}$ aluno é protagonista do aprender, sempre capacitando-se mais ainda a produzir, quando engajado nos processos. Estamos tratando de personalizar o ensino em que as potencialidades desenvolvidas partem das necessidades atendidas. Tais aspectos podem ser evidenciados nas necessidades dos alunos de hoje. Ensinar o que há de melhor no tradicional e culminar no que há de inovador com as tecnologias, o que podemos conceituar como ensino híbrido. Para Christensen (2015, p. 15)

Criar uma solução híbrida que dê aos educadores o melhor dos dois mundos - isto é, as vantagens do ensino on line combinadas com todos os benefícios da sala de aula tradicional. A opção disruptiva é empregar o ensino on-line em novos modelos que se afastem da sala de aula tradicional e foquem inicialmente nos não consumidores que valorizam a tecnologia pelo que ela é - mais adaptável, acessível e conveniente.

Neste cenário, enquanto "ensino híbrido", fazendo uso dos artefatos das tecnologias, mas tendo o aluno como o centro da aprendizagem, estamos considerando a autonomia porque este precisa nos dizer como aprende, seu ritmo, porque ele não vai aprender só nos 50 ou 60 min. de aula, estará interagindo mais e melhor com seu tempo e ampliando o tema da "aula", porque o conteúdo aplicado às situações da vida traz a evidência e precisão do por que aprender. 
Há diferentes possibilidades pedagógicas, como, por exemplo, agrupar por estações, com propostas diferenciadas, momento em que se supera a estrutura verticalizada da escola e propõe-se o engajamento e a entreajuda.

Chirstensein (2015), ao propor um programa de educação formal em que alie o online e o presencial, está indo além de nosso fazer pedagógico. Como pano de fundo há um controle do modo e do ritmo de aprender, texto, vídeo, situações reais do ensino, jornal, games. Utilizar e planejar as estratégias online com as aulas que serão trabalhadas propõe um ensino enriquecido com tecnologias digitais, integradas, as quais percebemos que são ferramentais que auxiliam nas metodologias a serem implementadas pelos professores.

Entendemos, ainda mais, a importância que o professor ganha nesse processo, porque se potencializa o ensino sim, mas só recurso por si pode não tornar a sala ativa. A tecnologia media a relação, mas não é o fim da aprendizagem. Ocorre uma triangulação entre professor-conteúdo-aluno e não uma verticalização em que o professor "que sabe" ensina "palestrando" para aquele que não sabe. Nesta triangulação, estamos abordando uma correlação em que haja um processo de aprendizagem que propicie o mesmo grau de envolvimento, tanto do professor quanto do aluno.

O conteúdo é um fio condutor das discussões e passa a ser trazido tanto pelo professor, quanto pelo aluno. O espaço é importante como um conceito próprio de relação, de diálogo e de corresponsabilidade de aprendizagem. A geografia da sala de aula muda, assim como a postura de cada sujeito.

No ensino híbrido, o espaço influencia tanto quanto a proposta de aprendizagem, até porque uma não se dá sem a outra. Por isso, os espaços convencionais precisam ser repensados. No papel de mediador, o professor é mais uma fonte, e ocupar diferentes espaços e trazer novos cenários são fios condutores de uma epistemologia do professor que acredita em seu educando. É preciso criar paradigmas, repensar as atividades que o professor organiza. Atividades formatadas para se adequar ao espaço e disrupção desse espaço. O professor intensifica sua ação, aproximando-se dos grupos diversos e suas atividades.

\section{A Inovação no Ensino Superior}

Assim como as mudanças da mobilidade digital têm incorporado modos de vida aos sujeitos, na vida educacional essas mudanças também vêm se desenhando no Ensino 
Superior. Inovar é a palavra de ordem porque traz em si a possibilidade de repensar processos e produtos. No caso da educação, nosso olhar está focado nos processos que nos possibilitam maiores aprendizagens.

O espaço da Universidade é, por vias naturais, o grande cenário em que se devem traduzir os saberes clássicos e os inovadores. Assim como os computadores estão cada vez mais avançados, ágeis e sendo passíveis de acesso em quaisquer lugares, as ferramentas de comunicação nos propiciam acesso a lugares e saberes antes não navegados. Nesse sentido, as Instituições de Ensino Superior trazem em si o critério dos saberes de vanguarda e propiciam o diálogo para o novo, o diferente e os aspectos focados no que se deve empreender.

Abordar a inovação disruptiva, no cenário acadêmico, é observar que o online passa a ocupar um outro lugar que vai muito além do sentido virtual. Essa nova composição entre o que se entende por online e o que remete ao presencial propõe uma nova configuração da construção da aula, levando em consideração que os usuários desses espaços são alunos com ambiência nas tecnologias. Para Horn, Christensen e Staker (2013, p. 7), "o ensino híbrido permite que esses estudantes aprendam online ao mesmo tempo em que se beneficiam da supervisão física e, em muitos casos, instrução presencial".

É importante salientar com os autores Horn, Christensen e Staker (2013, p. 8) que a "teoria da inovação disruptiva emergiu originalmente de um estudo sobre a indústria". Quando se buscam melhorias para ampliar a qualidade, manter a fidelidade de usuários aos serviços e ao consumo de produtos, unindo a tecnologia a estes, cria-se um híbrido, combinando, assim, a tecnologia antiga com a nova.

Novamente, a educação receptiva aos acontecimentos do meio, acresce diante do que pode inovar e, buscando as experiências norte-americanas, que a partir de 2012 são trazidas para nossa literatura, entendemos que é relevante observar o que a inovação disruptiva acrescenta como uma metodologia de construção de conhecimento.

Para Horn, Christensen e Staker (2013, p. 27), podemos entender o ensino híbrido por diferentes enfoques. Um deles é o de Rotação, "no qual, dentro de um curso ou matéria, os alunos revezam entre modalidades de ensino, em um roteiro fixo ou a critério do professor, sendo que, pelo menos uma modalidade, é a de ensino online”. Outras modalidades podem incluir atividades como as lições em grupos pequenos ou turmas completas, trabalhos em grupo, tutoria individual e trabalhos escritos. O modelo 
de Rotação tem quatro sub-modelos: rotação por estações, laboratório rotacional, sala de aula invertida e rotação individual.

Destacamos, aqui, que a sala de aula invertida é a prática que vem sendo pensada para ampliarmos nossas metodologias, oportunizando ao aluno de Ensino Superior uma aula presencial pelo professor e a aplicação de conteúdo e de atividades online para que seja mantida a introdução e/ou a continuidade da aula.

Tal proposição nasce por uma necessidade de ampliar o diálogo com os alunos no que tange à construção do conhecimento. As tradicionais aulas em que os professores estão numa constante palestra, acabam nem sempre desafiando o aluno a estudar e a pesquisar. São mudanças a longo prazo, e também acreditamos que os modos disruptivos de ensino híbrido melhorem favoravelmente as necessidades dos estudantes.

Não podemos deixar de salientar que a implementação de ensino híbrido está sendo desenhada para dentro de um espaço estruturado para um outro formato de ensino. Os alunos quando chegam às salas de aula, encontram-nas, basicamente, em fileiras perfiladas, localizadas em uma posição em que sempre verão o professor como o lócus do conhecimento. Quando se estrutura uma geografia diferente, o aluno também começa a entender que ele é sujeito de sua aprendizagem. Porém, no instante em que o professor, ao planejar a aula, apresenta elementos online e desafia o estudante a produzir sob suas leituras, há duas questões muito presentes e determinantes. A primeira delas sustenta-se na continuidade de uma exigência sobre o papel conjunto que é aprender: estar aberto para participar do processo, não ser um mero receptor, mas um sujeito leitor e pesquisador de sua própria aprendizagem. O segundo aspecto é o uso de ferramentas em que os alunos possuam ambiência, dada a cibercultura existente.

\section{Evidências de uma metodologia para o Ensino Superior}

Diante das bases conceituais sobre o ensino híbrido e a necessidade de a instituição buscar por novas práticas que denotem uma linguagem mais próxima dos acadêmicos, tendo em vista sua condição de sujeitos do processo de aprendizagem, destaco Cerutti e Giraffa (2015) quando salientam que é importante promover políticas e práticas a partir de programas institucionais, garantindo condições de participação com adesão voluntária.

Nesse sentido, as etapas do trabalho podem ser assim constituídas: 
a) Criar uma equipe autônoma em relação aos aspectos de uma aula tradicional. Horn, Christensen e Staker (2013, p. 40) destacam que "lançar um modelo disruptivo de ensino híbrido requer uma estratégia organizacional que vá além de formar uma equipe de pesos-pesados". Torna-se necessário criar uma independência, com modelos sobre recursos, processos e prioridades como proposta fundamental de valor.

b) Apoiar os gestores acadêmicos e administrativos que necessitam comprometer-se em projetar os projetos de ensino híbrido.

c) Ler, interpretar e entender a política de incentivo à inovação existente nas diferentes esferas, bem como o que as instituições educativas vêm realizando.

d) Gravar videoaulas diante da proposta de aprendizagem que o professor desejar trabalhar, antes da data da aula.

e) Disponibilizar para o aluno o vídeo e sugerir leitura da biblioteca digital ou indicar texto com cópia física, capaz de fazer uma leitura conceitual do que está abordando.

f) Aula invertida - os alunos assistem, leem e vêm para a aula com suas concepções a partir do que assistiram e leram.

g) Ao chegar em sala de aula o professor prepara sua aula a partir de uma situaçãoproblema da vida profissional, para os alunos trazerem soluções sobre o que assistiram e leram.

h) O professor orienta os grupos a partir da concepção dos alunos, sempre levando em consideração novas questões que vão surgindo.

Assim que as práticas forem todas planejadas e executadas, a Instituição fará um repositório de videoaulas, bem como uma publicação com todas as aulas produzidas pelos Departamentos, o que vai enriquecer a prática docente de todos os professores que terão esses colegas como guias para suas ações acadêmicas. A cada semestre, o grupo vai produzir novas aulas e serão convidados novos colegas para se inserirem no processo.

\section{Considerações finais}

As possibilidades aqui descritas são desafios a serem pensados nas Instituições, associados ao papel do professor em planejar a inserção do aluno na aula e possibilitar espaços cada vez maiores relacionados à interação. 
Certamente um trabalho como este requer dedicação, conscientização, estudo e reflexão sobre as abordagens, os processos e a revisão do andamento de cada etapa. Todos crescem neste âmbito e quem ganha são os acadêmicos que têm mais acesso à participação e envolvimento diante da construção da aula.

O fato é que carregamos conosco o ciberespaço e estamos mergulhados por propostas que nos convidam, tanto os acadêmicos como os docentes, a repensar seus processos. Há uma nova linguagem exposta nas Instituições que requer que tenhamos uma formação docente para a Pedagogia da Parceria diante do que podemos inserir como metodologia a partir do Ensino Híbrido.

Entendemos que tais possibilidades, enquanto metodologias, aliadas à interatividade, tão necessária a esta geração, possibilita ao professor instituir uma metodologia que proponha a ampla troca de ideias e a capacidade de dialogar sobre conteúdos. Entendemos que os jovens são íntimos diante dos códigos e procedimentos informacionais e o professor, ao fazer uso destes, ajusta seu modo de pensar e de construir conhecimento.

A universidade necessita redimir uma contradição que o cenário lhe apresenta: enquanto os alunos de hoje vivem difundidos com diversos dispositivos eletrônicos e digitais, ela continua obstinadamente arraigada em seus métodos e linguagens analógicos. Obviamente, a geração que chegou à Universidade possui a natividade digital e, em sua maioria, deseja aulas diferentes do que as instituições oferecem. A questão nova que se impõe está em fazer com as Universidades oportunizem aos seus professores espaços de vivências de ensino híbrido que possibilitem aos alunos aprenderem que sua ambiência digital pode ser melhor aproveitada para aprender.

Certamente, a discussão em torno das tecnologias digitais é muito mais complexa e fundamental do que se imagina. Por vezes, esperamos que a tecnologia se integre a um projeto pedagógico inovador, porém, o que pode ser inovador para o professor pode não ser para o aluno. Talvez ninguém saiba realmente em que consiste o ensino, e é muito duvidoso que os docentes contemporâneos possam assumir essa tarefa tendo-se dissolvido o mito da transmissão, sobretudo nesse campo em que os jovens parecem "saber" mais que eles; o significado de aprender passa a ser o alvo desses dois segmentos, alunos e professores.

Partindo deste pressuposto, é de grande importância que o professor esteja preparado para ter e utilizar as tecnologias como parceiras no processo de aprendizagem, bem como tenha capacidade crítica e conhecimento para enfrentar as 
contradições, as inconsistências e os perigos implícitos que as tecnologias apresentam. Para que esta inovação seja possível, é necessário que além do professor, a Universidade, também, mude sua metodologia, busque inovar e adaptar-se ao ferramental tecnológico que está disponível e que pode ser utilizado no processo de aprendizagem. Desse modo, a interação com o mundo virtual fará com que o educando busque explorar o material disponível e, assim, ampliar seu conhecimento de forma interativa e motivada.

À luz do ensino híbrido, temos possibilidades didáticas de propor aulas que o aluno, como ser ambientado à tecnologia, faz mais uso dela a favor de sua construção, compreendendo o significado de sua autonomia. Esses "dois mundos", o melhor do online, com o melhor do presencial, certamente fará com que o seu "aprender" esteja associado à questão do como eu aprendo e do que eu faço para aprender, isto é, do quanto me mobilizo para ser sujeito da aprendizagem.

Novamente, o foco da reflexão está no professor, como o problematizador de processos com atividades desafiadoras aos estudantes para que os mesmos exercitem sua criatividade e desenvolvam diferentes habilidades e competências. $\mathrm{O}$ trabalho com tecnologias vem de encontro a isso e mune o professor com diferentes alternativas para dar mais dinamicidade às suas aulas.

\section{REFERÊNCIAS}

ALMEIDA, M. E. B. de. e SILVA, M. da G. M. da. Currículo, tecnologia e cultura digital: espaços e tempos de web currículo. Revista e-curriculum, São Paulo, v.7 n.1, abril/2011.

BACICH, Lilian; NETO, Adolfo Tanzi; TREVISANI, Fernando de Mello (Orgs.).

Ensino híbrido: personalização e tecnologia na educação. Porto Alegre: Penso, 2015.

CERUTTI, Elisabete. GIRAFFA, Lucia Maria Martins. Uma nova juventude chegou à universidade: e agora, professor? 1. Ed. Curitiba, PR, CRV, 2015.

CHRISTENSEN, Claiton M; HORN, Micehael B; STAKER, Heather. Ensino Híbrido: uma Inovação Disruptiva? Uma introdução à teoria dos híbridos. Disponível em: <http://porvir.org/wp-content/uploads/2014/08/PT_Is-K-12-blended-learningdisruptive-Final.pdf $>$. Acesso em 28 de abr. 2016. 
CRISTENSEN, M.; HORN, M.; STAKER, H. Ensino híbrido: uma inovação disruptiva. Uma introdução à teoria dos híbridos. Instituto Península (Trad.). Fundação Lemann. Porto Alegre: Penso, 2013.

KENSKI, V. M. Tecnologias e ensino presencial e a distância. 3.ed. Campinas, SP: Papirus, 2003.

LÉVY P. O ciberespaço como um passo metaevolutivo. Porto Alegre: Sulina, 2004.

LÉVY P. Cibercultura: São Paulo, Editora 34, 1999.

LATOUR, Bruno. Ciência em ação: como seguir cientistas e engenheiros sociedade afora. Benedetti, Ivone (Trad.), 2 ed São Paulo: Editora Unesp, 2011.

MORAN, José Manuel. Desafios na Comunicação Pessoal. $3^{\text {a }}$ Ed. São Paulo: Paulinas, 2007.

PRENSKY, Marc. Teaching Digital Natives: Partnering for Real Learning. New York: Corwin, 2010.

SILVA, Rodrigo Abrantes da; CAMARGO, Ailton Luiz. A cultura escolar na era digital. In: BACICH, Lilian; NETO, Adolfo Tanzi; TREVISANI, Fernando de Mello (Orgs.). Ensino híbrido: personalização e tecnologia na educação. Porto Alegre: Penso, 2015.

RÜDIGER, Francisco. As teorias de cibercultura. Porto Alegre, RS: Sulina, 2011.

\section{Como referenciar este artigo}

CERUTTI, Elisabete.; MELO, Lucimauro Fernandes de. Abordagem híbrida no ensino superior: reflexões teórico-metodológicas. Revista on line de Política e Gestão Educacional, Araraquara/SP, v.21, n. esp. 1, p. 605-620, out./2017. Disponível em: <http://dx.doi.org/10.22633/rpge.v21.n.esp1.out.2017.9826>. ISSN: 1519-9029.

Submetido em: 13/05/2017

Aprovado em: 20/09/2017 